\title{
Influence of acidic monomer concentration and application mode on the bond strength of experimental adhesives
}

Cibele Cândida de Almeida KINTOPP(a)

Adilson Yoshio FURUSE ${ }^{(b)}$

Reginaldo Mendonça COSTA ${ }^{(b)}$

Fernanda Sandes de LUCENA ${ }^{(b)}$ (iD

Gisele Maria CORRER(a) (DD

Carla Castiglia GONZAGA ${ }^{(a)}$

(a) Universidade Positivo, School of Health Sciences, Graduate Program in Dentistry, Curitiba, PR, Brazil.

(b) Universidade de São Paulo - USP, Bauru School of Dentistry, Department of Operative Dentistry, Endodontics and Dental Materials, Bauru, SP, Brazil.

Declaration of Interests: The authors certify that they have no commercial or associative interest that represents a conflict of interest in connection with the manuscript.

\section{Corresponding Author:}

Carla Castiglia Gonzaga

E-mail: carlacgonzaga2@gmail.com

hitps://doi.org/10.1590/1807-3107bor-2020.vol34.0105

Submitted: January 28, 2020

Accepted for publication: June 15, 2020

Last revision: July 4, 2020
Abstract: The aim of this research was to evaluate the influence of MDP (10-methacryloyloxydecyl dihydrogen phosphate) concentration and application mode of experimental adhesives on microshear bond strength ( $\mu \mathrm{SBS})$ to dentin after storage in distilled water at $37^{\circ} \mathrm{C}$ for $24 \mathrm{~h}$ and 6 months. Five experimental adhesives were prepared with: CQ, DABE, BHT, ethanol, HEMA, TEGDMA, Bis-EMA, UDMA, and Bis-GMA. Concentrations of $0 \mathrm{wt} \%, 3 \mathrm{wt} \%, 9 \mathrm{wt} \%, 12 \mathrm{wt} \%$ or $15 \mathrm{wt} \%$ of MDP were added to their composition. The adhesives were applied to flat dentin surfaces in etch-and-rinse or self-etching modes. Cylindrical molds filled with light-cured composite resin were placed above the dentin. The specimens were stored in distilled water at $37^{\circ} \mathrm{C}$ for $24 \mathrm{~h}$ or 6 months and submitted to $\mu$ SBS testing. The adhesives were also submitted to $\mathrm{pH}$ analysis. The data were analyzed by one-way ANOVA, three-way ANOVA and Tukey's test $(\alpha=5 \%)$. All the adhesives used in the etch-and-rinse mode showed significantly higher bond strength than the adhesives applied in the self-etching approach. The $9 \mathrm{wt} \%$ adhesive showed the highest bond strength values, and $3 \mathrm{wt} \%$ was most stable after storage. A strong negative correlation between MDP concentration and $\mathrm{pH}$ was observed. It was concluded that the formulations with low concentrations of MDP (up to $9 \mathrm{wt} \%$ ) showed better results for bond strength and bond strength degradation over time.

Keywords: Dental Bonding; Dentin-Bonding Agents; Adhesives; Dental Marerials.

\section{Introduction}

Functional monomers can make the bond strength more resistant and durable between composite resin and adhesive systems, and between adhesive systems and tooth structures. ${ }^{1}$ Among these monomers, 10-methacryloyloxydecyl dihydrogen phosphate (MDP) is an ester of acidic constitution that forms a low solubility calcium salt, capable of interacting with hydroxyapatite by chemical bonding to the $\mathrm{Ca}^{2+}$ ions in the collagen fibrils or the hybrid layer, in forming MDP-Ca salt. ${ }^{2,3,4,5}$ The deposition of MDP-Ca salt produces an acid-resistant zone, since this salt increases the 
resistance to solubility significantly, compared with the salts produced by other functional monomers. $3,6,7,8$

The characteristics of a dental adhesive formulation can influence its effectiveness directly. Among these characteristics, the $\mathrm{pH}$ and amount of water in the adhesive system can influence smear layer removal. Water functions as an ionizing medium in the bonding of the released $\mathrm{Ca}^{2+}$ ions to the MDP molecule, forming the MDP-Ca salt. ${ }^{9}$ The amount of water in MDP-based adhesives plays a role in the bond strength to dentin. An increase in the amount of water in experimental adhesives has been found to increase their ability to demineralize and remove the smear layer. ${ }^{9}$ However, dentin solubilization decreased the bond strength before and after thermocycling.

Adhesive procedures require smear layer treatment to increase the interaction with the dental substrate. Whereas the smear layer is completely removed by acid etching with etch-and-rinse adhesives, self-etching adhesives need a different approach, based on the $\mathrm{pH}$ of the primer or bonding agents. On the other hand, universal adhesives are similar to single-bottle one-step self-etch adhesive systems, and can be used with etch-and-rinse, selfetching, or selective enamel-etching modes. ${ }^{10}$ Selfetching adhesives are classified according to their acidity as follows: strong $(\mathrm{pH} \leq 1)$, intermediate $(\mathrm{pH} \sim 1.5)$, and mild $(\mathrm{pH} \geq 2){ }^{1}$ A new group of selfetching adhesives called "ultra-mild" have been introduced on the market. These adhesives have low acidity $(\mathrm{pH} \sim 2.7)$. This $\mathrm{pH}$ value promotes reduced smear layer dissolution, and allows a thin smear layer to be obtained. ${ }^{11,12}$ The $\mathrm{pH}$ plays a major role, since it has been shown that bond strength to dentin is increased when ultra-mild MDP-containing universal adhesives are used with the etch-and-rinse technique. ${ }^{13,14}$

Incorporation of MDP into the formulation of adhesive systems has been found to significantly improve their bond strength and reduce hybrid layer degradation over time..$^{15,16,17}$ Some studies have evaluated the bond strength of adhesives containing different concentrations of MDP in an attempt to correlate these different concentrations of functional monomers to bond strength to dentin;, $8,18,19,20$ however, the data are still inconclusive, and the ideal concentration of MDP for adhesive systems could not as yet be established. Functional monomers such as MDP may interact with the amine from the $\mathrm{CQ} /$ amine light activation system through an acidbase reaction, and compromise the polymerization efficiency of experimental adhesives. ${ }^{21}$ Thus, it may be hypothesized that high amounts of MDP can compromise bonding to dentin in the long term.

A study comparing five adhesives with different MDP concentrations (0 to $15 \mathrm{wt} \%$ ) showed that the amount of MDP influenced the amount of MDP-Ca salt formed, and this influenced the bond strength to bovine dentin after 30,000 thermal cycles. ${ }^{18}$ Another study that evaluated the bond strength and degree of conversion of adhesives containing 0 to $20 \mathrm{wt} \%$ of MDP showed that different concentrations of MDP influenced the bond strength, and that experimental adhesive with $10 \mathrm{wt} \%$ MDP showed the best combination of bond strength and degree of conversion. ${ }^{19}$ Therefore, studies that evaluate the influence of different MDP concentrations on adhesive systems are particularly relevant for both the development of restorative materials and clinical practice.

In this respect, this study aimed to evaluate the influence of different concentrations of MDP ( $0 \mathrm{wt} \%$ to $15 \mathrm{wt} \%$ ) on microshear bond strength to dentin of the tested experimental adhesives, after storage in distilled water at $37^{\circ} \mathrm{C}$ for 24 hours and 6 months, when used in etch-and-rinse and self-etching modes. The null hypotheses were that a) the different concentrations of MDP would not influence the dentin bond strength; b) the application mode (etch-andrinse or self-etching) would not influence the bond strength to dentin; and c) the storage time would not influence the bond strength of the adhesives tested.

\section{Methodology}

Five experimental adhesives were evaluated according to their percentage of MDP $(0 \mathrm{wt} \%, 3 \mathrm{wt} \%$, $9 \mathrm{wt} \%, 12 \mathrm{wt} \%$, and $15 \mathrm{wt} \%$ ). These adhesives were applied as etch-and-rinse and self-etching systems, except for the adhesive with $0 \mathrm{wt} \% \mathrm{MDP}$, which was used only in the etch-and-rinse mode. The tested adhesives and application protocols are described in Table 1. 
Table 1. Composition of the experimental adhesives.

\begin{tabular}{|c|c|c|}
\hline Composition (by weight) & \multicolumn{2}{|c|}{ Application protocol } \\
\hline $\begin{array}{l}\text { Basic composition consists of: } 0.5 \% \text { CQ, } 1 \% \\
\text { DABE, } 0.2 \% \text { BHT, } 10 \% \text { ethanol, 10\% HEMA, } \\
15 \% \text { TEGDMA, 25\% Bis-EMA, 25\% UDMA, } \\
\text { and } 12.85 \% \text { Bis-GMA. }\end{array}$ & Etch-and-rinse & Self-etching \\
\hline \multirow{6}{*}{$\begin{array}{l}\text { MDP\% added to the basic composition: } \\
0 \%, 3 \%, 9 \%, 12 \% \text { or } 15 \%\end{array}$} & $\begin{array}{l}\text { 1. Apply } 37 \% \text { phosphoric acid (Condac } \\
\text { 37, FGM, Joinville, SC, Brazil) for } 15 \mathrm{~s}\end{array}$ & 1. Apply two adhesive layers \\
\hline & $\begin{array}{l}\text { 2. Apply water spray and rinse conditioned } \\
\text { areas thoroughly for } 10 \mathrm{~s}\end{array}$ & $\begin{array}{l}\text { 2. Disperse adhesive and remove solvent } \\
\text { with dry air from an air-water syringe } \\
\text { for } 10 \mathrm{~s}\end{array}$ \\
\hline & $\begin{array}{l}\text { 3. Remove rinsing water with absorbent } \\
\text { paper, without desiccating dentin }\end{array}$ & 3. Light cure for $10 \mathrm{~s}$ \\
\hline & 4. Apply two adhesive layers & \\
\hline & $\begin{array}{l}\text { 5. Disperse adhesive and remove solvent } \\
\text { with dry air from an air-water syringe } \\
\text { for } 10 \mathrm{~s}\end{array}$ & \\
\hline & 6. Light activate for $10 \mathrm{~s}$ & \\
\hline
\end{tabular}

HEMA: 2-hydroxyethyl methacrylate; bis-GMA: glycerolate dimethacrylate; DABE: 1,2 diaminobenzene; CQ: camphorquinone; BHT: butylated hydroxytolvene; DPIHP: diphenyliodonium hexafluorophosphate; TEGDMA: triethylene glycol dimethacrylate; Bis-EMA: ethoxylated bisphenol A dimethacrylate; UDMA: urethane dimethacrylate; MDP: 10-methacryloyloxydecyl dihydrogen phosphate.

Ninety extracted caries-free human third molars were used in the study after approval by the Institutional Review Board (CAAE 50831915.6.0000.0093, approval protocol 1.350.250). The crowns were separated from the roots, cut in half in the mesiodistal direction, and each half was embedded in PVC cylinders $(1.2 \times 2.5$ $\mathrm{cm}$ ) using self-curing acrylic resin (Jet, São Paulo, Brazil), with the exposed flat dentin surface facing up. Smear layers were standardized by wet-sanding dentin surfaces with 600-grit silicon carbide paper (Buehler MetaSerc 250, Lake Bluff, USA) for $1 \mathrm{~min}$ under copious water irrigation.

Dentin surfaces were then randomly distributed within the groups, according to the adhesive to be tested (MDP $0 \mathrm{wt} \%, 3 \mathrm{wt} \%, 9 \mathrm{wt} \%, 12 \mathrm{wt} \%$, and $15 \mathrm{wt} \%$ ), the mode of application (except for the adhesive with 0\% MDP, which is not indicated for self-etch application), and storage time (24 hours and 6 months). The adhesive procedures began by delimiting the dentin surfaces with perforated double-sided tape. The adhesives were applied according to the protocols described in Table 1. Light activation was performed with an LED device (Poly Wireless, Kavo, Joinville, Brazil) operating in standard mode with an output irradiance of $1100 \mathrm{~mW} / \mathrm{cm}^{2}$.
Transparent cylindrical molds $0.7 \mathrm{~mm}$ in diameter and $1 \mathrm{~mm}$ high (Tygon tubes, R-3603, Saint-Gobain Performance Plastics, Miami Lakes, USA) were positioned on the hybridized dentin surfaces, and the internal volume was filled with composite resin (Filtek Z350 XT, 3M ESPE, St. Paul, USA). The resin cylinders were light activated for $30 \mathrm{~s}$. After $10 \mathrm{~min}$, the molds were removed to expose composite resin cylinders with a bonding area of $0.38 \mathrm{~mm}^{2}$. Half of the specimens were stored in distilled water at $37^{\circ} \mathrm{C}$ for $24 \mathrm{~h}$, whereas the other half were stored in distilled water at $37^{\circ} \mathrm{C}$ for 6 months.

The $\mu$ SBS ( $\mathrm{n}=10$ ) was evaluated using the wireloop method, in a universal testing machine (DL2000, EMIC, São José dos Pinhais, Brazil) operating at a crosshead speed of $0.5 \mathrm{~mm} / \mathrm{min}$ and using a $50 \mathrm{kgf}$ load cell. To this end, the teeth were aligned to allow loading the steel wire-loop ( $0.2 \mathrm{~mm}$ diameter) to be placed as closely as possible to the bonded interface, at the base of the composite resin cylinders. The $\mu$ SBS (in $\mathrm{MPa}$ ) was calculated by dividing the maximum force (in N) by the bonded area (in $\mathrm{mm}^{2}$ ). Debonded surfaces were examined by a single observer, under a stereomicroscope at 57x magnification (SZX9, Olympus, Tokyo, Japan), to determine the failure mode. Failures were classified as adhesive (at the bonding interface), 
cohesive (in dentin or in composite resin) or mixed. The experimental adhesives were also submitted to $\mathrm{pH}$ analysis. The $\mathrm{pH}$ values were determined using $3 \mathrm{~mL}$ of each adhesive, at room temperature (22 to $25^{\circ} \mathrm{C}$ ), using a digital $\mathrm{pH}$ meter (PG2000, GEHAKA, São Paulo, Brazil).

The $\mu$ SBS data were analyzed by one-way ANOVA separately for $24 \mathrm{~h}$ and 6 months to analyze the effect of MDP concentration. These analyses included the MDP $0 \mathrm{wt} \%$ groups. In addition, three-way ANOVA was also performed to test MDP concentration (except for MDP $0 \mathrm{wt} \%$ ), application mode and storage time. All the analyses were followed by applying Tukey's HSD test. The correlation between the MDP concentration of experimental adhesives and bond strength, and between $\mathrm{pH}$ and bond strength, were performed using Spearman's rank correlation coefficient. The correlation between $\mathrm{pH}$ and MDP concentration was performed using Pearson's correlation coefficient. All analyses were performed with a significance level of $5 \%$.

\section{Results}

Microshear bond strength values for the experimental adhesives according to MDP concentration, mode of application and storage time are described in Table 2 . The $\mathrm{pH}$ values determined for all formulations are also shown in Table 2, and ranged from $3.2(9 \mathrm{wt} \% \mathrm{MDP})$ to $5.2(0 \mathrm{wt} \% \mathrm{MDP})$.
One-way ANOVA indicated significant differences in the adhesives $(p<0.001)$ for both the 24 -h and the 6 -month time periods. There were no differences regarding the MDP concentrations among the etch-and-rinse groups in the 24-h storage period, or among the self-etch groups in the same period. However, there were significant differences between the etch-and-rinse and the self-etching modes for the same MDP concentration. As for the 6-month storage period, there were no differences in the MDP concentrations among the self-etch groups. However, among the etch-and-rinse groups, $3 \mathrm{wt} \%$ MDP showed the highest bond strength value, statistically similar to $9 \mathrm{wt} \% \mathrm{MDP}$, but higher than the other MDP concentrations.

Three-way ANOVA indicated statistically significant differences for MDP concentration $(\mathrm{p}=0.006)$, application mode $(\mathrm{p}<0.001)$ and storage time $(p<0.001)$. All double interactions were statistically significant $(\mathrm{p}<0.05)$, except for MDP concentration*application mode $(p=0.190)$. The triple interaction was also significant $(\mathrm{p}=0.010)$. As for MDP concentration, the range in bond strength values observed the following order: $9 \mathrm{wt} \% \mathrm{MDP}$ $(9.40 \pm 7.50 \mathrm{MPa})^{\mathrm{a}}, 12 \mathrm{wt} \% \mathrm{MDP}(7.89 \pm 5.80 \mathrm{MPa})^{\mathrm{ab}}$, $3 \mathrm{wt} \% \mathrm{MDP}(7.58 \pm 6.17 \mathrm{MPa})^{\mathrm{ab}}$, and $15 \mathrm{wt} \% \mathrm{MDP}$ $(6.37 \pm 5.49 \mathrm{MPa})^{\mathrm{b}}$. All adhesives used in the etch-and-rinse mode $(12.17 \pm 6.08 \mathrm{MPa})$ showed significantly higher bond strength than the adhesives

Table 2. Mean values and standard deviations for the bond strength values according to MDP concentration, application mode and storage time.

\begin{tabular}{|c|c|c|c|c|}
\hline \multirow{2}{*}{ MDP concentration } & \multirow{2}{*}{$\mathrm{pH}$} & \multirow{2}{*}{ Application mode } & \multicolumn{2}{|c|}{ Storage time } \\
\hline & & & $24 \mathrm{~h}$ & 6 months \\
\hline $0 \mathrm{w}+\% \mathrm{MDP}$ & 5.2 & Etch-and-rinse & $13.85(9.40)^{\mathrm{A}}$ & $6.52(3.43)^{B C D}$ \\
\hline \multirow{2}{*}{$3 \mathrm{wt} \% \mathrm{MDP}$} & \multirow{2}{*}{4.3} & Etch-and-rinse & $11.55(7.42)^{\mathrm{AB}}$ & $13.11(4.60)^{\mathrm{A}}$ \\
\hline & & Self-etch & $4.40(2.45)^{B C}$ & $2.49(1.20)^{\mathrm{E}}$ \\
\hline \multirow{2}{*}{$9 \mathrm{wt} \% \mathrm{MDP}$} & \multirow{2}{*}{3.2} & Etch-and-rinse & $18.94(6.27)^{\mathrm{A}}$ & $9.62(3.34)^{A B}$ \\
\hline & & Self-etch & $5.92(4.84)^{\mathrm{BC}}$ & $2.84(1.86)^{D E}$ \\
\hline \multirow{2}{*}{$12 \mathrm{wt} \% \mathrm{MDP}$} & \multirow{2}{*}{3.3} & Etch-and-rinse & $15.20(5.71)^{\mathrm{A}}$ & $7.33(2.72)^{B C}$ \\
\hline & & Self-etch & $5.75(3.20)^{B C}$ & $3.81(2.51)^{\mathrm{CDE}}$ \\
\hline \multirow{2}{*}{$15 w+\%$ MDP } & \multirow{2}{*}{3.3} & Etch-and-rinse & $13.46(5.21)^{\mathrm{A}}$ & $7.95(2.36)^{\mathrm{B}}$ \\
\hline & & Self-etch & $2.64(1.50)^{\mathrm{C}}$ & $1.74(1.16)^{\mathrm{E}}$ \\
\hline
\end{tabular}

Values followed by the same letter in each column (24 h and 6 months, one-way ANOVA and Tukey's HSD test) are statistically similar ( $p>0.05)$. 
applied in the self-etching mode $(3.75 \pm 2.94 \mathrm{MPa})$. Regarding storage time, the bond strength after 6 months $(6.12 \pm 4.80 \mathrm{MPa})$ was significantly lower compared to $24 \mathrm{~h}(9.47 \pm 7.31 \mathrm{MPa})$. Figure 1 shows the pairwise comparisons among the means of all the groups (Tukey's test following three-way ANOVA).

Figure 2 shows that, the coefficient of determination $\left(\mathrm{R}^{2}\right)$ between bond strength and MDP concentration, after the second-degree polynomial, ranged from 0.345 to 0.937 . A strong negative correlation between MDP concentration and $\mathrm{pH}$ was found for the experimental adhesives, highlighting Pearson's correlation coefficient of -0.908 and $p=0.033$ (Figure 3 ). Correlations between bond strength values ( $\mu \mathrm{SBS}$ ) and MDP concentration (\% MDP), and between $\mathrm{pH}$ and bond strength, for both application modes evaluated, were weak to moderate and non-significant.

The failure mode analysis showed that all groups presented predominantly adhesive (93\% to $100 \%)$ and mixed (0 to $7 \%$ ) failures. No group presented a cohesive failure, regardless of MDP concentration, application mode or storage time.

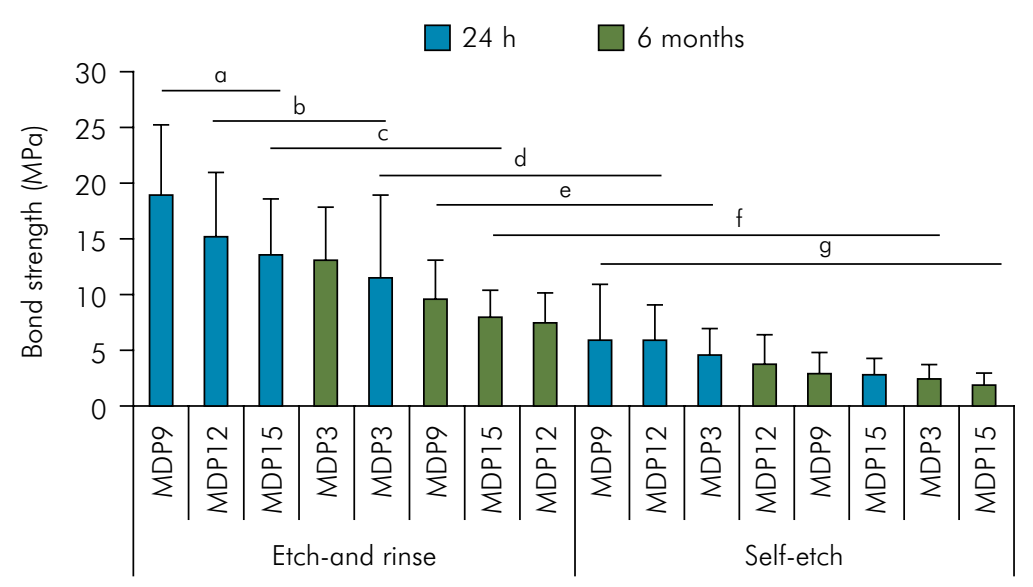

Figure 1. Bar plot showing the $\mu \mathrm{SBS}$ means and standard deviations for all the groups. Groups sharing the same horizontal line and letter are statistically similar $(p>0.05)$.

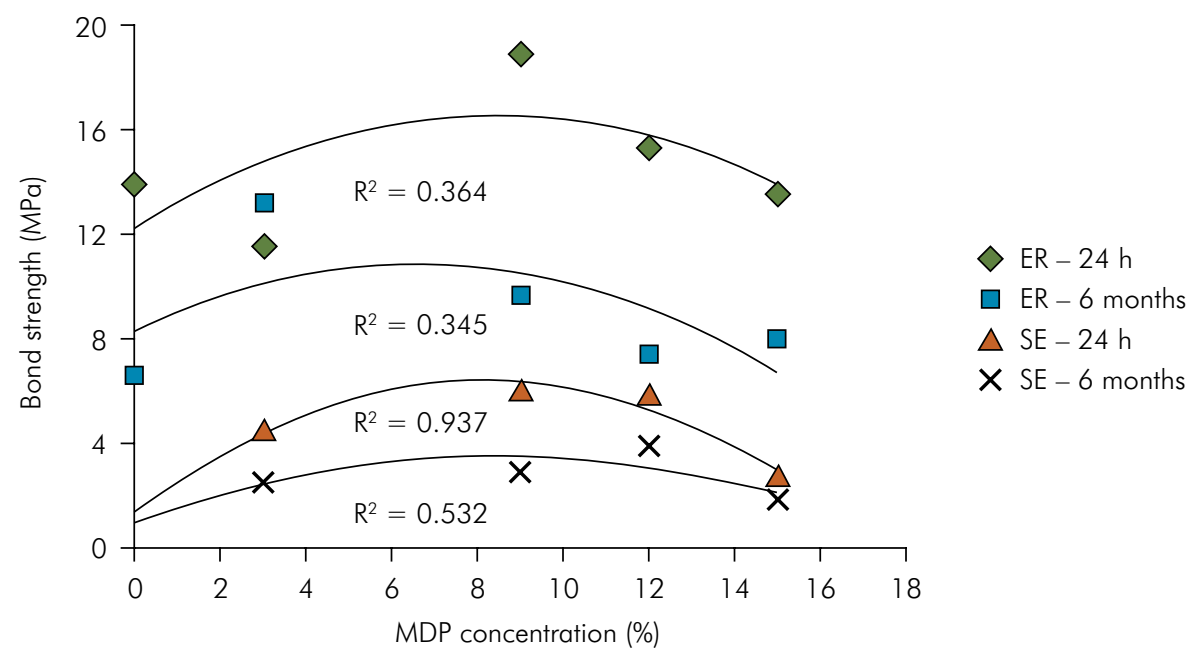

Figure 2. Correlation between bond strength (24 hours and 6 months) and MDP concentration for the experimental adhesives, according to the application mode. 


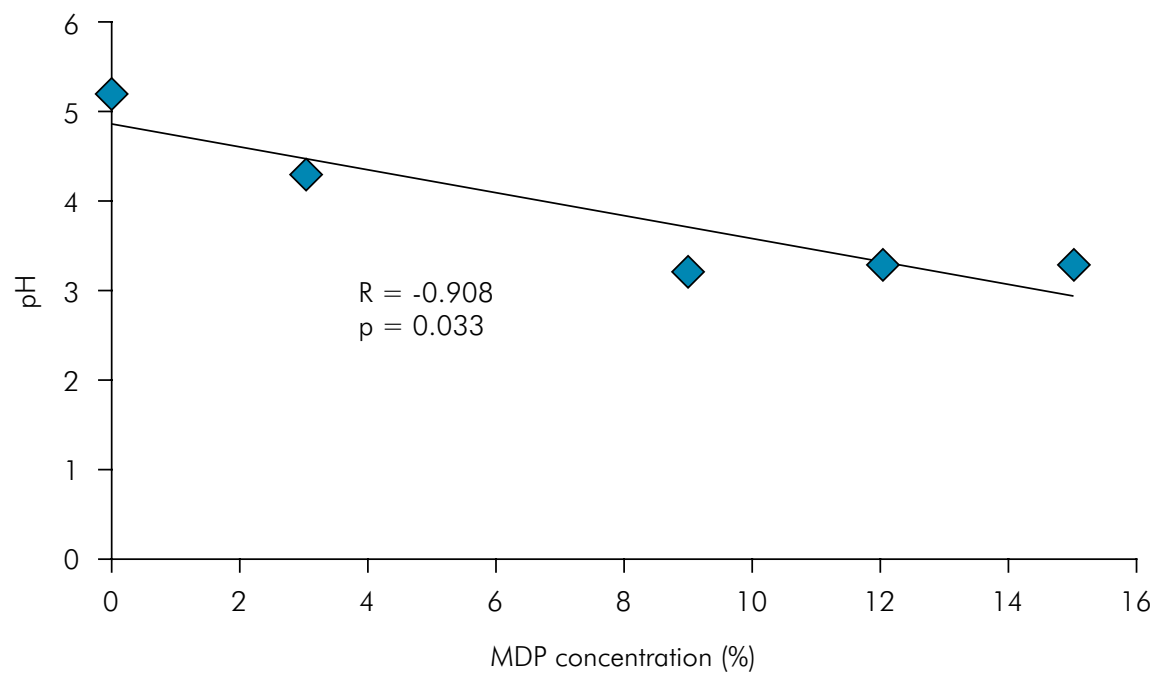

Figure 3. Correlation between $\mathrm{pH}$ and MDP concentration for the experimental adhesives.

\section{Discussion}

The experimental adhesives, especially $9 \mathrm{wt} \%$ MDP, showed the highest bond strength values in both modes of application, indicating that the MDP concentration incorporated into the adhesive may influence bonding to dentin. On the other hand, the bond strength of the $3 \mathrm{wt} \%$ MDP adhesive was not significantly affected by storage, and showed only a slight increase. This information confirms the ability of MDP to preserve bonding to dentin from the effects of hydrolysis. This can be attributed to the additional chemical interaction promoted by MDP when bonding with calcium ions to form a strong acid-base zone, which influences bond strength positively. ${ }^{18}$ A previous study also tested the range of MDP percentages by weight, between 0 and $20 \%$, in the experimental self-etching adhesives. It showed that formulations with $10 \%$ and $15 \%$ provided higher bond strength. ${ }^{19}$

The differences found in the $\mu$ SBS values of the experimental adhesives evaluated may be influenced by other factors, such as the composition of the adhesives. Adhesives may contain different combinations of monomers, concentrations, amounts of water, other solvents and $\mathrm{pH}$ levels..$^{22,23}$ However, a specific MDP concentration used in the composition of the experimental adhesives presented in this study could have influenced their bond strength performance. It can be observed that different MDP concentrations resulted in different bond strength values, suggesting that there may be an "ideal" concentration of MDP that is more appropriate for a specific composition.

The composition used for the experimental adhesives in this study may differ significantly from that of the commercially available adhesives. The composition of the commercial adhesives, regarding components and percentages used, is not entirely disclosed by the manufacturers, making it difficult to make comparisons between commercial and experimental adhesives. Because MDP has an acidic monomer, chemical bonding with the dental structure may occur. This is because the MDP monomer bonds with the $\mathrm{Ca}^{2+}$ ions deposited under the collagen layer or in the hybrid layer in the self-etching approach, to form the MDP-Ca salt. $5,24,25$ In fact, the results of the present study show that the amount of MDP is important not only for bonding, but also for hydrolytic stability.

The present study observed that the etch-and-rinse mode of application showed higher bond strength values than the self-etching mode, regardless of MDP concentration. The $\mathrm{pH}$ analyses demonstrate that the experimental adhesives used in this study were ultra-mild despite the amount of MDP. Except for the $3 \mathrm{wt} \%$ MDP adhesive ( $\mathrm{pH} 4.3$ ), all the other adhesives showed $\mathrm{pH} 3.2$ to 3.3. This may explain why the etch-and-rinse mode showed better results. It was also 
observed that the etch-and-rinse approach used with an ultra-mild MDP-based universal adhesive ( $\mathrm{pH}$ 3.1) improved the bonding to dentin, compared with the self-etch mode. ${ }^{14}$ Hence, the adhesives evaluated in the present study were found to be better suited for use with an etch-and-rinse approach, despite of the amount of MDP. This result is in agreement with a recently published systematic review. ${ }^{13}$ Several types of functional monomers have been used in different self-etching and universal adhesive systems. Universal adhesives can be used with self-etch, selective-etch and total-etch bonding systems. The composition of the present experimental adhesive can be understood as being that of a universal adhesive system, which includes a functional monomer (MDP), and can be used with both strategies. The results of this study also indicate that the experimental adhesive used behaved like a universal adhesive, since relatively high bond strengths were observed for both application modes, even after six months of water storage. The function of MDP is not completely clear when universal adhesives are used in an etch-and-rinse mode. However, it has been previously reported that this monomer may interact chemically with collagen. ${ }^{26}$

Use of $37 \%$ phosphoric acid in dentin for $15 \mathrm{~s}$ in self-etching adhesive systems is not indicated. The use of acid as a separate step has the purpose of demineralizing the hydroxyapatite, and opening space in the dentinal tubules for penetration of the adhesive monomers and exposure of the collagen web to form the hybrid layer. However, this formation occurs more frequently with self-etching adhesives, owing to their more hydrophilic structure, because a greater amount of water forms a more permeable and less resistant hybrid layer. ${ }^{24,25}$

On the one hand, a study analyzing the bond strength and penetration of three adhesive systems, with and without acid etching, after 24 hours and 5000 thermal cycles, concluded that acid etching improved dentin penetration, without interfering in the bond strength. ${ }^{4}$ On the other hand, another study evaluated three commercial adhesives with MDP in their composition, in etch-and-rinse and self-etching modes of application. It showed that the acid etching of the etch-and-rinse system enabled the formation and penetration of a hybrid layer, and a more efficient and thicker acid resistant zone than that formed by the self-etching adhesive system. ${ }^{23}$

The data shown in Table 2 and Figure 1 indicate that the experimental adhesives did not show good performance for the bond strength test in the selfetching mode. The $\mathrm{pH}$ values of the formulations evaluated in the present study indicated that the acids in the self-etching systems were weak. The literature reports that self-etching adhesives usually have a $\mathrm{pH}$ of about 2, which is enough to act on the hybrid layer efficiently and allow incorporation of the monomers. ${ }^{1,27}$

\section{Conclusions}

It can be concluded that MDP concentration and application mode influenced the bond strength of the experimental adhesive systems evaluated. The formulations with low concentration of MDP (up to $9 \mathrm{wt} \%$ ) showed better results for bond strength and bond strength degradation over time. No significant correlations were observed between bond strength and MDP concentration, or between $\mathrm{pH}$ and bond strength, for neither of the application modes evaluated. A strong negative correlation between MDP concentration and $\mathrm{pH}$ was found for the experimental adhesives. Regarding the application mode, the etch-and-rinse approach presented higher bond strength values for the tested compositions than the self-etching application mode.

\section{Acknowledgments}

The authors acknowledge the contribution of FGM Dental Products (Joinville, SC, Brazil) in preparing the experimental adhesives used in this study.

\section{References}

1. De Munck J, Van Landuyt K, Peumans M, Poitevin A, Lambrechts P, Braem M, et al. A critical review of the durability of adhesion to tooth tissue: methods and results. J Dent Res. 2005 Feb;84(2):118-32. https://doi.org/10.1177/154405910508400204 
Influence of acidic monomer concentration and application mode on the bond strength of experimental adhesives

2. Yoshida Y, Van Meerbeek B, Nakayama Y, Snauwaert J, Hellemans L, Lambrechts P, et al. Evidence of chemical bonding at biomaterialhard tissue interfaces. J Dent Res. 2000 Feb;79(2):709-14. https://doi.org/10.1177/00220345000790020301

3. Fukegawa D, Hayakawa S, Yoshida Y, Suzuki K, Osaka A, Van Meerbeek B. Chemical interaction of phosphoric acid ester with hydroxyapatite. J Dent Res. 2006 Oct;85(10):941-4. https://doi.org/10.1177/154405910608501014

4. Wagner A, Wendler M, Petschelt A, Belli R, Lohbaver U. Bonding performance of universal adhesives in different etching modes. J Dent. 2014 Jul;42(7):800-7. https://doi.org/10.1016/i.jdent.2014.04.012

5. Yoshihara K, Yoshida Y, Nagaoka N, Fukegawa D, Hayakawa S, Mine A, et al. Nano-controlled molecular interaction at adhesive interfaces for hard tissue reconstruction. Acta Biomater. 2010 Sep;6(9):3573-82. https://doi.org/10.1016/i.actbio.2010.03.024

6. Li N, Nikaido T, Takagaki T, Sadr A, Makishi P, Chen J, et al. The role of functional monomers in bonding to enamel: acid-base resistant zone and bonding performance. J Dent. 2010 Sep;38(9):722-30. https://doi.org/10.1016/i.jdent.2010.05.015

7. Nikaido T, Ichikawa C, Li N, Takagaki T, Sadr A, Yoshida Y, et al. Effect of functional monomers in all-in-one adhesive systems on formation of enamel/dentin acid-base resistant zone. Dent Mater J. 2011;30(5):576-82. https://doi.org/10.4012/dmj.2010-214

8. Iwai H, Nishiyama N. Effect of calcium salt of functional monomer on bonding performance. J Dent Res. 2012 Nov;91(11):1043-8. https://doi.org/10.1177/0022034512458925

9. Teshima M. Effect of the concentration of water in an MDP-based all-in-one adhesive on the efficacy of smear layer removal and on dentin bonding performance. Dent Mater J. 2018 Jul;37(4):685-92. https://doi.org/10.4012/dmj.2017-291

10. Chen C, Niu LN, Xie H, Zhang ZY, Zhou LQ, Jiao K, et al. Bonding of universal adhesives to dentine_old wine in new bottles? J Dent. 2015 May;43(5):525-36. https://doi.org/10.1016/i.jdent.2015.03.004

11. Suyama Y, Lührs AK, De Munck J, Mine A, Poitevin A, Yamada T, et al. Potential smear layer interference with bonding of self-etching adhesives to dentin. J Adhes Dent. 2013 Aug;15(4):317-24. https;//doi.org/10.3290/i.jad.a29554 ·

12. Koshiro K, Sidhu SK, Inove S, Ikeda T, Sano H. New concept of resin-dentin interfacial adhesion: the nanointeraction zone. J Biomed Mater Res B Appl Biomater. 2006 May;77(2):401-8. https://doi.org/10.1002/jbm.b.30450

13. Cuevas-Suárez CE, Rosa WL, Lund RG, Silva AF, Piva E. Bonding performance of universal adhesives: an updated systematic review and meta-analysis. J Adhes Dent. 2019;21(1):7-26.

14. Rosa WL, Piva E, Silva AF. Bond strength of universal adhesives: a systematic review and meta-analysis. J Dent. 2015 Jul;43(7):765-76. https://doi.org/10.1016/i.jdent.2015.04.003

15. Yoshida Y, Inove YY. Chemical analyses in dental adhesive technology. Jpn Dent Sci Rev. 2012;48(2):141-52. https://doi.org/10.1016/j.jdsr.2012.03.001

16. do Amaral RC, Stanislawczuk R, Zander-Grande C, Gagler D, Reis A, Loguercio AD. Bond strength and quality of the hybrid layer of onestep self-etch adhesives applied with agitation on dentin. Oper Dent. 2010 Mar-Apr;35(2):211-9. https://doi.org/10.2341/09-198-L

17. Zander-Grande C, Loguercio AD, Stanislawczuk R, Martins GC, Gomes OM, Reis A. The effect of 6-month water storage on the bond strength of self-etch adhesives bonded to dentin. Am J Dent. 2011 Aug;24(4):239-44.

18. Takahashi H. Effect of calcium salt of 10 -methacryloyloxydecyl dihydrogen phosphate produced on the bond durability of one-step selfetch adhesive. Dent Mater J. 2014;33(3):394-401. https://doi.org/10.4012/dmi.2014-008

19. Yazdi FM, Moosavi H, Atai M, Zeynali M. Dentin bond strength and degree of conversion evaluation of experimental self-etch adhesive systems. J Clin Exp Dent. 2015 Apr;7(2):e243-9. https://doi.org/10.4317/jced.51842

20. Matsui N, Takagaki T, Sadr A, Ikeda M, Ichinose S, Nikaido T, et al. The role of MDP in a bonding resin of a two-step self-etching adhesive system. Dent Mater J. 2015;34(2):227-33. https://doi.org/10.4012/dmj.2014-205

21. Hanabusa M, Yoshihara K, Yoshida Y, Okihara T, Yamamoto T, Momoi Y, et al. Interference of functional monomers with polymerization efficiency of adhesives. Eur J Oral Sci. 2016 Apr;124(2):204-9. https://doi.org/10.1111/eos.12245

22. Grégoire G, Sharrock P, Prigent Y. Performance of a universal adhesive on etched and non-etched surfaces: do the results match the expectations? Mater Sci Eng C. 2016 Sep;66:199-205. https://doi.org/10.1016/j.msec.2016.04.022

23. Guan R, Takagaki T, Matsui N, Sato T, Burrow MF, Palamara J, et al. Dentin bonding performance using Weibull statistics and evaluation of acid-base resistant zone formation of recently introduced adhesives. Dent Mater J. 2016 Jul;35(4):684-93. https://doi.org/10.4012/dmi.2016-059

24. Tay FR, Frankenberger R, Krejci I, Bouillaguet S, Pashley DH, Carvalho RM, et al. Single-bottle adhesives behave as permeable membranes after polymerization. I. In vivo evidence. J Dent. 2004 Nov;32(8):611-21. https://doi.org/10.1016/i.jdent.2004.04.006

25. Tay FR, Pashley DH. Dental adhesives of the future. J Adhes Dent. 2002;4(2):91-103.

26. Hiraishi N, Tochio N, Kigawa T, Otsuki M, Tagami J. Monomer-collagen interactions studied by saturation transfer difference NMR. J Dent Res. 2013 Mar;92(3):284-8. https://doi.org/10.1177/0022034512474310

27. Fujita-Nakajima K, Aoki-Tabei N, Arita A, Nishiyama N. NMR study on the demineralization mechanism of the enamel and dentin surfaces in MDP-based all-in-one adhesive. Dent Mater J. 2018 Jul;37(4):693-701. https://doi.org/10.4012/dmi.2017-292 